\section{A Randomized Comparison of Off-Pump and On-Pump Multivessel Coronary-Artery Bypass Surgery}

\author{
Natasha E. Khan, M.R.C.S., Anthony De Souza, F.R.C.S., Rebecca Mister, M.Sc., \\ Marcus Flather, F.R.C.P., Jonathan Clague, M.D., Simon Davies, F.R.C.P., \\ Peter Collins, M.D., Duolao Wang, Ph.D., Ulrich Sigwart, M.D., \\ and John Pepper, M.Chir.
}

A B STRACT

BACK GROUN D

The effect of the use of coronary-artery bypass surgery without cardiopulmonary bypass and cardiac arrest ("off pump") on graft patency remains uncertain. We undertook a prospective, randomized, controlled study to compare graft-patency rates and clinical outcomes in off-pump surgery with conventional, "on-pump" surgery.

\section{METHODS}

We randomly assigned 50 patients to undergo on-pump coronary-artery bypass grafting and 54 to undergo off-pump surgery. Surgical and anesthetic techniques were standardized for both groups. Clinical outcomes and troponin T levels were measured. Three months later, the patients underwent coronary angiography, including quantitative analysis.

\section{RESULTS}

The mean age of the patients was 63 years, and 87 percent were men. The on-pump group received a mean of 3.4 grafts, and the off-pump group $3.1(\mathrm{P}=0.41)$. There were no deaths. There was no significant difference in the median postoperative length of stay between the two groups (seven days in each group). The area under the curve of troponin $T$ levels was higher during the first 72 hours in the on-pump group than in the off-pump group $(30.96 \mathrm{hr} \cdot \mu \mathrm{g}$ per liter vs. $19.33 \mathrm{hr} \cdot \mu \mathrm{g}$ per liter, $\mathrm{P}=0.02)$. At three months, 127 of 130 grafts were patent in the on-pump group ( 98 percent), as compared with 114 of 130 in the off-pump group ( 88 percent, $\mathrm{P}=0.002$ ). The patency rate was higher for all graft territories in the on-pump group than in the off-pump group.

CONCLUSIONS

In this randomized study, off-pump coronary surgery was as safe as on-pump surgery and caused less myocardial damage. However, the graft-patency rate was lower at three months in the off-pump group than in the on-pump group, and this difference has implications with respect to the long-term outcome.
From the Royal Brompton and Harefield National Health Service Trust (N.E.K., A.D.S., R.M., M.F., J.C., S.D.); the Imperial College of Science, Technology, and Medicine, National Heart and Lung Institute (P.C., J.P.); and the London School of Hygiene and Tropical Hygiene (D.W.) - all in London; and the Center and Division of Cardiology, University Hospital, Geneva (U.S.). Address reprint requests to $D r$. Khan at the Clinical Trials and Evaluation Unit, Royal Brompton Hospital, London SW3 6NP, United Kingdom, or at r.mister@rbh.nthames.nhs.uk.

N Engl J Med 2004;350:21-8.

Copyright $\odot 2004$ Massachusetts Medical Society. 
ORONARY-ARTERY BYPASS GRAFTING performed with cardiopulmonary bypass and cardiac arrest ("on pump") provides a motionless, bloodless surgical field, allowing optimal conditions for the construction of coronary anastomoses. Cardiopulmonary bypass is believed by many to be a major cause of postoperative morbidity, including neuropsychological impairment, ${ }^{1,2}$ and the resurgence of interest in surgery without cardiopulmonary bypass ("off pump") reflects an attempt to avoid the morbidity associated with cardiopulmonary bypass. ${ }^{3-5}$

The development of modern stabilizers has made off-pump coronary surgery accessible and technically feasible. ${ }^{6}$ There is evidence that as compared with on-pump surgery, off-pump surgery may decrease the incidence of myocardial injury, ${ }^{7}$ renal damage, ${ }^{8}$ and injury to the brain. ${ }^{9}$ Previous randomized studies have shown a shorter length of stay, a reduced use of transfusion products, a reduced incidence of coagulopathy, and a lower frequency of atrial fibrillation in patients who undergo off-pump surgery. ${ }^{10-12}$ On the other hand, there is some evidence that off-pump surgery increases the risk of recurrent angina and the need for reintervention, suggesting poor graft quality or incomplete revascularization. ${ }^{13,14}$

There is insufficient evidence from randomized studies comparing graft patency in patients undergoing off-pump coronary surgery with graft patency in those undergoing on-pump surgery, and there have been few studies of unselected patients requiring multivessel grafting. We evaluated graft patency and quality in a randomized study comparing onpump with off-pump surgery.

\section{METHODS}

\section{STUDY DESIGN AND PATIENTS}

This was a prospective, randomized study performed at a single center. Patients who were referred for isolated, first-time coronary-artery surgery and who required at least three grafts were eligible. All angiograms were reviewed, and a surgical plan was documented before randomization. Exclusion criteria were as follows: an age of less than 30 years or more than 80 years; an indication for additional surgical procedures; documented stroke within the preceding six months; carotid-artery stenosis of more than 70 percent; documented myocardial infarction in the preceding three months; poor left ventricular function, with an ejection fraction of less than
20 percent; pregnancy and breast-feeding; an inability to provide written informed consent; and a history of complications after diagnostic angiography.

The Royal Brompton and Harefield Research Ethics Committee approved the study. Written informed consent was obtained from all patients. Patients were randomly assigned in equal proportions to undergo on-pump or off-pump coronary-artery bypass grafting. Randomization was stratified according to the surgeon, so that both surgeons performed similar numbers of on- and off-pump procedures. We began to perform off-pump surgery two years before the study began. During this period, 98 of 753 isolated coronary-artery bypass grafts (13 percent) performed by the participating surgeons were done off pump.

\section{TREATMENT AND PROCEDURES}

Troponin Twas measured in patients as a marker of cardiac damage. Levels were measured at base line (during the induction of anesthesia) and at 6, 12, 24,48 , and 72 hours. Samples were spun and frozen to $-80^{\circ} \mathrm{C}$ within 30 minutes after collection and were analyzed in batches. Samples were analyzed for cardiac troponin $T$ with the use of the Troponin T STAT Immunoassay (Elecsys 1010/2010 Systems, Roche).

A standardized anesthetic protocol was used throughout the study. Cardiopulmonary bypass was established in a standardized manner, with the use of a membrane oxygenator and a roller pump and without the use of cardiotomy suction. The heart was exposed through a median-sternotomy incision. The Octopus stabilizer (Medtronic) was used for the off-pump group. During on-pump surgery, patients were cooled to $32^{\circ} \mathrm{C}$, whereas during offpump surgery, patients were actively warmed to maintain a core temperature not lower than $35^{\circ} \mathrm{C}$. Cold-blood cardioplegia was accomplished with anterograde delivery through the aortic root and retrograde delivery through the coronary sinus. A heparinization protocol of $300 \mathrm{U}$ per kilogram for on-pump surgery and half-dose heparin for offpump surgery was followed. Protamine was used to reverse the effects of heparinization only in the on-pump group. All anastomoses were sutured by hand. In the off-pump group, intracoronary shunts were not used routinely; indications for use included poor visibility, ST-segment changes, and hemodynamic instability. A standardized protocol for immediate postoperative care was followed in the adult intensive care unit, including antiplatelet therapy 
(300 mg of aspirin six hours after surgery, followed by a daily dose of $150 \mathrm{mg}$ ).

\section{FOLLOW-UP}

All patients were followed for three months after the operation, at which time they were scheduled to undergo coronary angiography. Adverse events and symptom status were recorded for all patients, including those who were not willing to return for angiography. Left-heart catheterization was performed with the use of a standard Judkins technique by an experienced interventional cardiologist. Whenever possible, the pedicled left internal thoracic-artery graft was selectively intubated, and images were obtained in multiple projections. When grafts could not be identified, an aortogram was obtained. Native vessels were investigated only if a blocked graft was found. All angiograms were interpreted by an interventional cardiologist who was unaware of the patients' original study assignments and who did not perform the repeated angiography. Patency was defined as any flow through both the graft and the native vessel. The graft was said to be nonpatent if a stump was seen or if there was no flow on the aortogram.

Images were acquired digitally in a Siemens cardiac catheter laboratory calibrated for spatial distortion for quantitative coronary angiography. All digital images were analyzed in a blinded fashion by an experienced observer. The optimal frame and projection were selected to show the anastomosis of the left internal thoracic artery to the left anterior descending artery with the least foreshortening and overlap and then analyzed with the use of CMS software, version 4.1 (Medis). Automated edge detection was then manually adjusted, and stenoses at the point of anastomosis were quantified both as the minimal luminal diameter in absolute measurements (millimeters) and as the percentage of the reference diameter, which was the normal diameter of the left internal thoracic artery just proximal to the anastomosis.

\section{STATISTICAL ANALYSIS}

The study was powered to detect a difference in the minimal luminal diameter between the on-pump and off-pump groups of $0.3 \mathrm{~mm}$, with an assumed standard deviation of $0.5 \mathrm{~mm}$ (a power of 80 percent and a two-sided alpha level of 0.05), given the enrollment of 100 patients. Means $( \pm S D)$ were used to describe the continuous variables, and frequencies were calculated for categorical variables. Dif- ferences between treatment groups were compared with the use of a two-sided type I error Student's t-test or the Mann-Whitney U test for continuous variables. The chi-square test was used for categorical variables. To analyze data on plasma troponin T levels, the area under the concentration-time curve was calculated by the trapezoidal method for each patient, and treatment-related differences in the area under the curve were then compared by Student's $\mathrm{t}$-test. The outcome variables were analyzed on an intention-to-treat basis. All reported P values are two-sided. No interim analyses were carried out during the course of this study.

\section{RESULTS}

\section{patient population}

From January 2000 to January 2002, 104 patients underwent randomization: 50 to on-pump surgery and 54 to off-pump surgery. One patient in the onpump group was found to have inoperable lung carcinoma after randomization and did not undergo coronary-artery bypass grafting. The analyses are based on the remaining 103 patients.

Most base-line characteristics were similar in the two groups (Table 1); the mean age was 64.7 years in the on-pump group and 62.0 years in the off-pump group. The distribution of patients in Canadian Cardiovascular Society classes and New York Heart Association classes was similar in the two groups. There was a significant difference in the mean planned number of grafts (3.6 in the on-pump group vs. 3.2 in the off-pump group, $\mathrm{P}=0.003$ ). Twenty-seven percent of patients had diabetes, and 44 percent of patients had had a myocardial infarction.

\section{OPERATIVE DATA}

Intraoperative data are given in Table 1 . Two patients who were randomly assigned to off-pump surgery were switched intraoperatively to on-pump surgery, owing to intractable ventricular tachycardia in one patient and to an intramyocardial left anterior descending artery in the other. There was no significant difference in the quality of the native vessels between the two groups, as assessed by the surgeon with the use of a simple qualitative scale. The numbers of grafts per patient were similar in the two groups (3.4 in the on-pump group and 3.1 in the off-pump group), as were the territories grafted. The index of completeness (the number of grafts performed $\div$ the number of grafts planned) was sim- 


\begin{tabular}{|c|c|c|c|}
\hline Characteristic & $\begin{array}{l}\text { On-Pump } \\
\text { Group } \\
(\mathrm{N}=49)\end{array}$ & $\begin{array}{l}\text { Off-Pump } \\
\text { Group } \\
(\mathrm{N}=54)\end{array}$ & $\begin{array}{c}P \\
\text { Value }\end{array}$ \\
\hline Age $-y r$ & $64.7 \pm 8.4$ & $62.0 \pm 7.9$ & 0.10 \\
\hline Male sex - no. (\%) & $40(82)$ & $50(93)$ & 0.09 \\
\hline $\begin{array}{l}\text { Left ventricular function — \% } \\
\text { Good }(E F>49 \%) \\
\text { Fair }(E F=30-49 \%) \\
\text { Poor }(E F<30 \%)\end{array}$ & $\begin{array}{r}73 \\
27 \\
0\end{array}$ & $\begin{array}{r}76 \\
22 \\
2\end{array}$ & 0.57 \\
\hline $\begin{array}{l}\text { Canadian Cardiovascular Society class } \\
\quad \text { - no. (\%) } \\
\text { 0, I, or II } \\
\text { III or IV }\end{array}$ & $\begin{array}{l}29(59) \\
20(41)\end{array}$ & $\begin{array}{l}29(54) \\
25(46)\end{array}$ & 0.70 \\
\hline Previous myocardial infarction — no. (\%) & $24(49)$ & $21(39)$ & 0.30 \\
\hline $\begin{array}{l}\text { Previous cerebrovascular accident } \\
\quad \text { - no. (\%) }\end{array}$ & $2(4)$ & $3(6)$ & 0.73 \\
\hline Diabetes — no. (\%) & $13(26)$ & $15(28)$ & 0.86 \\
\hline Planned no. of grafts & $3.6 \pm 0.6$ & $3.2 \pm 0.7$ & 0.003 \\
\hline Creatinine $-\mu \mathrm{mol} /$ liter $\uparrow$ & $94.8 \pm 20.0$ & $95.0 \pm 23.9$ & 0.96 \\
\hline \multicolumn{4}{|l|}{ Intraoperative variables } \\
\hline $\begin{array}{l}\text { Duration of cardiopulmonary bypass } \\
\text { - } \min \end{array}$ & $101.16 \pm 24.67$ & NA & NA \\
\hline Duration of ischemia - min & $60.23 \pm 14.46$ & NA & NA \\
\hline No. of grafts & $3.4 \pm 0.7$ & $3.1 \pm 0.6$ & 0.41 \\
\hline Index of completeness & $0.95 \pm 0.02$ & $0.99 \pm 0.02$ & 0.16 \\
\hline $\begin{array}{l}\text { Territory grafted - no. (\%) } \\
\text { Left internal thoracic to left anterior } \\
\text { descending artery }\end{array}$ & $49(100)$ & $52(96)$ & 0.34 \\
\hline Circumflex or obtuse marginal artery & $40(82)$ & $43(80)$ & 0.80 \\
\hline $\begin{array}{l}\text { Right coronary or posterior descend- } \\
\text { ing artery }\end{array}$ & $42(86)$ & $44(81)$ & 0.56 \\
\hline $\begin{array}{l}\text { Native-vessel quality — no. (\%) } \\
\quad \text { Poor } \\
\text { Fair } \\
\text { Good }\end{array}$ & $\begin{array}{c}15(9) \\
44(27) \\
107(64)\end{array}$ & $\begin{array}{r}16(10) \\
44(26) \\
107(64)\end{array}$ & 0.98 \\
\hline $\begin{array}{l}\text { Type of graft - no. (\%) } \\
\text { Free internal thoracic artery } \\
\text { Pedicled internal thoracic artery } \\
\text { Radial artery } \\
\text { Saphenous vein }\end{array}$ & $\begin{aligned} &(6) \\
& 46(94) \\
& 27(55) \\
& 36(73)\end{aligned}$ & $\begin{aligned} & 2(4) \\
52 & (96) \\
40 & (74) \\
40 & (74)\end{aligned}$ & $\begin{array}{l}0.57 \\
0.26 \\
0.04 \\
0.94\end{array}$ \\
\hline $\begin{array}{l}\text { Intraoperative conversion to the other } \\
\text { approach }- \text { no. }\end{array}$ & 0 & 2 & NA \\
\hline Time required per anastomosis $-\mathrm{min}$ & $9.5 \pm 3.1$ & $13.1 \pm 4.9$ & $<0.001$ \\
\hline Duration of procedure $-\min$ & $237.8 \pm 40.4$ & $237.6 \pm 41.5$ & 0.98 \\
\hline
\end{tabular}

* Plus-minus values are means \pm SD. EF denotes ejection fraction, and NA not applicable.

$\uparrow$ To convert values for creatinine to milligrams per deciliter, divide by 88.4 .

ilar in the two groups. A higher proportion of patients in the off-pump group than in the on-pump group received radial-artery grafts $(74$ percent vs. 55 percent, $\mathrm{P}=0.04$ ), and the mean time required per anastomosis was longer in the off-pump group (13.1 minutes vs. 9.5 minutes, $\mathrm{P}<0.001$ ).

\section{IM MEDIATE POSTOPERATIVE PERIOD}

Table 2 shows the postoperative data and adverse events. There were no deaths. In the on-pump group, two patients required resternotomy because of hemorrhage during the immediate postoperative period. In the off-pump group, there was a single myocardial infarction. The mean blood loss was not significantly different between the two groups $(898 \mathrm{ml}$ in the on-pump group and $1031 \mathrm{ml}$ in the off-pump group). However, patients in the on-pump group were more likely to receive packed-cell transfusion $(\mathrm{P}=0.004)$ or clotting-product transfusion $(\mathrm{P}=$ 0.002 ). There was no significant difference in the mean time to extubation or the median postoperative hospital stay between the two groups.

Figure 1 shows mean troponin T levels over time in the two groups. Troponin T levels were significantly higher in the on-pump group than in the offpump group 6 and 12 hours postoperatively ( $\mathrm{P}<$ 0.001 for both comparisons), but this difference had disappeared by 24 hours. There was a significant difference in the mean area under the curve of troponin T values $(30.96 \mathrm{hr} \cdot \mu \mathrm{g}$ per liter in the onpump group and $19.33 \mathrm{hr} \cdot \mu \mathrm{g}$ per liter in the offpump group, $\mathrm{P}=0.02$ ).

\section{THREE-MONTH FOLLOW-UP AND ANGIOGRAPHY} At three months, the distribution of patients in $\mathrm{Ca}$ nadian Cardiovascular Society classes and New York Heart Association classes was similar in the two groups, as was the incidence of adverse events, including hospitalization. No deaths, myocardial infarctions, or cerebrovascular accidents occurred during this time.

Follow-up angiographic data were available for 82 patients (39 patients in the on-pump group and 43 in the off-pump group) (Table 3 ). The remainder were not willing to undergo repeated angiography. There were no systematic clinical differences between those who underwent repeated angiography and those who did not. Table 3 and Figure 2 show the patency rates in each territory. The overall patency rate for grafts performed on pump was significantly higher than the patency rate for those performed off pump ( 98 percent vs. 88 percent, $\mathrm{P}=$ 0.002). This difference was observed in the territory of the right coronary artery $(\mathrm{P}=0.01)$ and the territory of the left anterior descending artery $(\mathrm{P}=0.07)$. Significantly more radial-artery grafts were used in 
the off-pump group, with a lower patency rate in this group than in the on-pump group (76 percent vs. 100 percent, $\mathrm{P}=0.01$ ).

\section{QUANTITATIVE CORONARY ANGIOGRAPHY}

Table 3 shows the quantitative coronary angiographic analysis of the anastomosis of the left internal thoracic artery to the left anterior descending artery. There was no significant difference between the groups in the percentage of stenosis measured at this site, although there was a trend toward a higher percentage of stenosis in the off-pump group than in the on-pump group (mean, 34.67 \pm 34.53 percent vs. $21.19 \pm 26.38$ percent, $\mathrm{P}=0.06$ ).

\section{I SCUSSION}

We found that the patency rate for grafts performed off pump was lower at three months than that for grafts performed on pump (overall patency, 88 percent vs. 98 percent). The territory of the left anterior descending artery, often described as the easiest territory to graft off pump, also had a lower rate of patency in the off-pump group. Radial-artery grafts appear to be the most vulnerable conduit in the offpump group.

We have considered possible reasons for the reduced patency rate in our off-pump group. The anticoagulation regimen differed in this group, with only half-dose heparinization during the formation of the anastomoses. This practice is widely accepted, ${ }^{15}$ and there have been no reports to suggest that it increases the risk of graft occlusion. All patients in both groups received the same regimen of antiplatelet therapy. The two surgeons performed similar numbers of on-pump and off-pump procedures for the study. In the two years preceding the study, the surgeons performed 13 percent of their coronary work off pump. Off-pump surgery is technically more demanding than on-pump surgery because the operative field is less stable and less visible. The learning curve for this procedure is probably substantial and may be longer than we anticipated. One should bear this in mind when interpreting our results. We used an unselected population of patients, many of whom had diseased target vessels. A more selective approach to the target vessel might yield better results for off-pump surgery.

We chose to perform angiography at three months, since any edema at the site of anastomosis would have resolved by this time. The rate of compliance with repeated coronary angiography was

\begin{tabular}{|c|c|c|c|}
\hline Variable & $\begin{array}{l}\text { On-Pump } \\
\text { Group } \\
(\mathrm{N}=49)\end{array}$ & $\begin{array}{l}\text { Off-Pump } \\
\text { Group } \\
(\mathrm{N}=54)\end{array}$ & $\begin{array}{c}P \\
\text { Value }\end{array}$ \\
\hline Death - no. & 0 & 0 & NA \\
\hline Major adverse event - no. & 2 & 1 & 0.50 \\
\hline Low cardiac output — no. (\%) & $17(35)$ & $13(24)$ & 0.24 \\
\hline Time to extubation - $\mathrm{hr}$ & $12.6 \pm 5.9$ & $11.9 \pm 7.8$ & 0.63 \\
\hline Reopening for hemorrhage - no. (\%) & $2(4)$ & 0 & 0.13 \\
\hline Peripheral-wound infection - no. (\%) & $5(10)$ & 0 & 0.02 \\
\hline Median stay in adult ICU $-\mathrm{hr}$ & 24 & 24 & 0.86 \\
\hline Median postoperative hospital stay - days & 7 & 7 & 0.08 \\
\hline Blood loss - $\mathrm{ml}$ & $898 \pm 434$ & $1031 \pm 552$ & 0.18 \\
\hline $\begin{array}{l}\text { Need for transfusion — no. (\%) } \\
\text { Packed cells } \\
\text { Clotting products }\end{array}$ & $\begin{array}{l}32(65) \\
14(29)\end{array}$ & $\begin{array}{c}20(37) \\
2(4)\end{array}$ & $\begin{array}{l}0.004 \\
0.002\end{array}$ \\
\hline
\end{tabular}

* Plus-minus values are means \pm SD. NA denotes not applicable, and ICU intensive care unit.

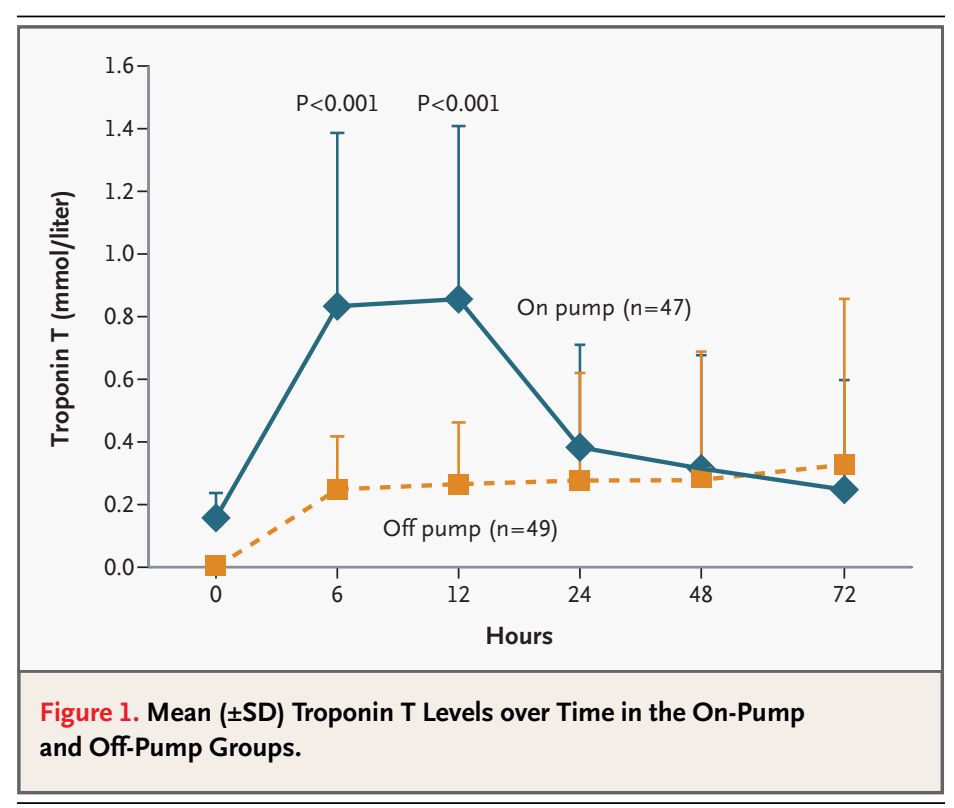

80 percent, which compares favorably with compliance rates in other studies. ${ }^{15}$ We measured differences in the quality of the anastomosis of the left internal thoracic artery to the left anterior descending artery, using previously described techniques, ${ }^{16}$ and these results reflect our patency rate.

Our findings with respect to clinical outcomes and troponin $\mathrm{T}$ levels are consistent with findings from other studies of off-pump surgery, showing 


\begin{tabular}{|c|c|c|c|c|}
\hline Variable & On-Pump Group & Off-Pump Group & P Value & Absolute Difference $(95 \% \mathrm{Cl})$ \\
\hline \multicolumn{5}{|l|}{ Patency rate - no./total no. (\%) } \\
\hline Overall & $127 / 130(98)$ & $114 / 130(88)$ & 0.002 & 10 (3.8 to 16.2$)$ \\
\hline Left anterior descending artery & $40 / 40 \quad(100)$ & $35 / 38 \quad(92)$ & 0.07 & $8(-0.1$ to 16.5$)$ \\
\hline Circumflex artery & $35 / 37 \quad(95)$ & $33 / 38 \quad(87)$ & 0.25 & $8(-5.3$ to 20.7$)$ \\
\hline Right coronary artery & $35 / 35 \quad(100)$ & $31 / 37 \quad(84)$ & 0.01 & $16(4.3$ to 28.1$)$ \\
\hline Pedicled left internal thoracic artery & $47 / 47 \quad(100)$ & $46 / 50 \quad(92)$ & 0.05 & $8(0.5$ to 15.5$)$ \\
\hline Radial artery & $22 / 22 \quad(100)$ & $26 / 34 \quad(76)$ & 0.01 & 24 (9.3 to 37.8$)$ \\
\hline Saphenous vein & $56 / 59$ (95) & $40 / 44 \quad(91)$ & 0.42 & $4(-6.1$ to 14.2$)$ \\
\hline \multicolumn{5}{|l|}{ Quantitative coronary angiography $\dagger$} \\
\hline Reference diameter $-\mathrm{mm}$ & $2.06 \pm 0.40$ & $2.11 \pm 0.64$ & 0.65 & $0.50(-0.29$ to 0.19$)$ \\
\hline Luminal diameter $-\mathrm{mm}$ & $1.63 \pm 0.68$ & $1.46 \pm 0.93$ & 0.37 & $0.17(-0.20$ to 0.54$)$ \\
\hline Stenosis - \% of reference diameter & $21.19 \pm 26.38$ & $34.67 \pm 34.53$ & 0.06 & $-13.48(-27.51$ to 0.55$)$ \\
\hline
\end{tabular}

* Plus-minus values are means \pm SD. $\mathrm{Cl}$ denotes confidence interval.

$\dagger$ Follow-up angiographic data were available for 39 patients in the on-pump group and 43 in the off-pump group.

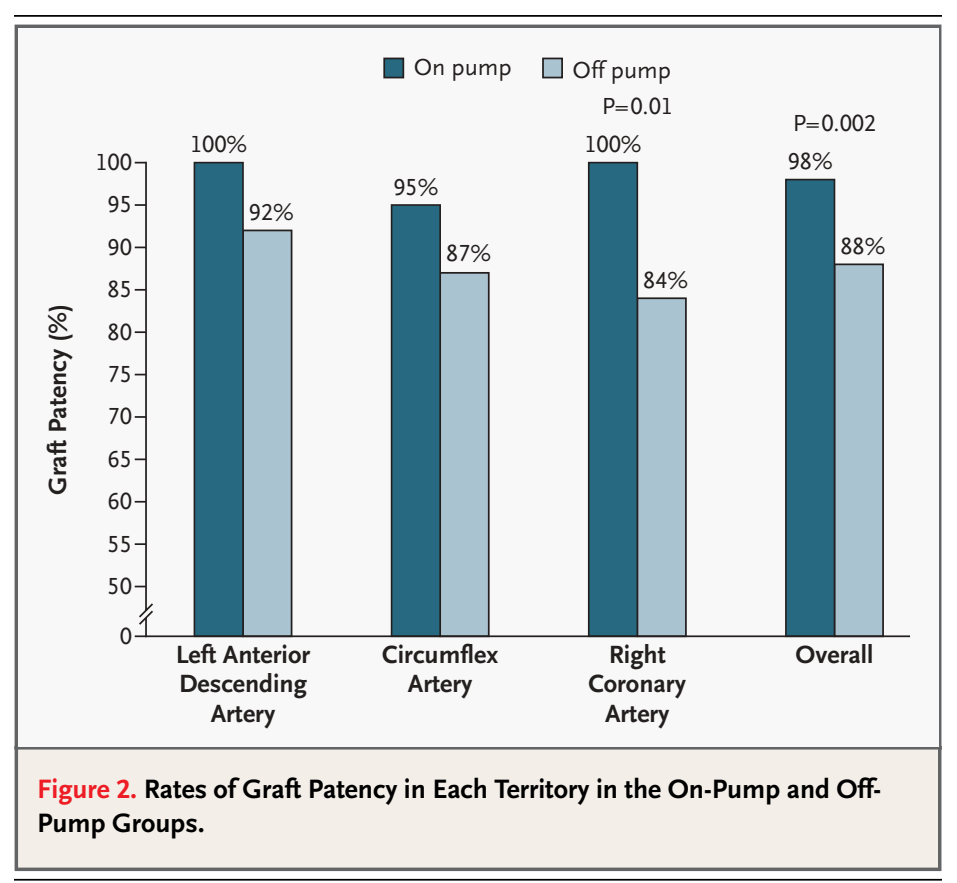

reduced release of cardiac-specific proteins and a low rate of adverse events. ${ }^{10-12}$ However, the rate of graft patency in our off-pump group was lower than that in the few other studies in which this was investigated. ${ }^{15,17}$ The only other randomized study investigating graft patency found no significant differences in patency rates between the two groups, but only 25 percent of patients were reevaluated. ${ }^{15}$ In that study, the overall patency rate was 93 percent in the on-pump group and 91 percent in the off-pump group (absolute difference, 2.0 percentage points; 95 percent confidence interval, 6.5 to 10.4). The on-pump patency rate was lower than in our study ( 93 percent vs. 98 percent); our rate of 98 percent in the on-pump group is at the high end of the reported range and may skew the results. The absence of a significant difference in patency rates in the earlier study may be due in part to the small proportion of patients who underwent repeated angiography. Another important difference is that the number of grafts per patient was lower in that study than in ours (2.6 in the on-pump group and 2.4 in the off-pump group, as compared with 3.4 and 3.1, respectively).

Nonrandomized studies have consistently shown excellent patency rates for off-pump surgery, but the majority of these studies involved patients who were receiving one or two grafts, with a lower proportion of patients receiving circumflex-artery grafts, indicating a highly selected population. ${ }^{17-19}$ Other studies have included low-risk patients with preserved left ventricular function who required one or two grafts. ${ }^{15,18}$ Our patients represent a population with true multivessel disease; a quarter of our patients had a left ventricular ejection fraction of less than 50 percent, and almost half of our patients had a previous myocardial infarction. Twenty- 
seven percent of patients in our study had diabetes, as compared with 17 percent in the on-pump group and 9 percent in the off-pump group in the study by Nathoe et al. 15

Troponin $\mathrm{T}$ levels were higher in the on-pump group than in the off-pump group 6 and 12 hours postoperatively, but this difference had disappeared by 24 hours. The area under the curve, representing total protein release, confirms that the level was higher in the on-pump group. These short-lived elevations in the levels of troponin $\mathrm{T}$ may not represent true myocyte death or injury. ${ }^{20}$

Short-term outcomes in terms of major adverse events at discharge and at three months were similar in the two groups. In the immediate postoperative period, fewer patients in the off-pump group required transfusions of blood or clotting products. The difference may be clinically important. However, the use of protocol-driven care in the immediate postoperative period and hemodilution may account in part for the difference.

The practice of off-pump coronary surgery has not been widely adopted; only 8.8 percent of all coronary-artery bypass operations performed in the United States between January 1999 and January 2001 were performed off pump. ${ }^{21}$ Mack et al. ${ }^{22}$ found that off-pump surgery is performed to a large extent by early pioneers in the field, who - even before the advent of off-pump surgery - were the surgeons in their units whose patients had lower operative mortality rates and better outcomes. Thus, previous off-pump results may be better because the surgeons who choose to perform this operation are highly skilled. ${ }^{22}$ In contrast to the findings of Mack et al. and in answer to the questions raised by Bonchek in the editorial accompanying their report, ${ }^{23}$ we have shown that the surgeon's skill was not a factor in our results, since our surgeons had a high rate of on-pump patency and there were no deaths in either group.

Thus, although off-pump coronary surgery may not be widely applicable, it may be a useful strategy in selected patients, such as those with serious coexisting conditions who have good target vessels. The apparently reduced patency rate in the off-pump group in our study arouses concern about the longterm outcome of this approach, and further clinical trials with longer follow-up are needed.

Supported by grants from the British Heart Foundation (PG/ 9912) and the Royal Brompton and Harefield National Health Service Trust Clinical Research Committee.

We are indebted to Medtronic Inc. for kindly supplying the Octopus II equipment for the study free of cost, to James Hooper and Michael Kemp for advice on the biochemical markers and performance of the laboratory analysis, to Marcelo Shibata for help in the design of the study, and to Fiona Nugara for data management.

Dr. Flather, Prof. Pepper, and Prof. Sigwart report having received research grants for separate studies from Medtronic Inc., and Prof. Pepper and Dr. De Souza report having served as consultants for Medtronic Inc.
REFERENCES

1. Roach GW, Kanchuger M, Mangano CM, et al. Adverse cerebral outcomes after coronary bypass surgery. N Engl J Med 1996;335: 1857-63.

2. Newman MF, Kirchner JL, Phillips-Bute $\mathrm{B}$, et al. Longitudinal assessment of neurocognitive function after coronary-artery bypass surgery. N Engl J Med 2001;344:395402. [Erratum, N Engl J Med 2001;344:1876.] 3. Buffolo E, de Andrade CS, Branco JN, Teles CA, Aguiar LF, Gomes WJ. Coronary artery bypass grafting without cardiopulmonary bypass. Ann Thorac Surg 1996;61: 63-6.

4. Benetti FJ, Naselli G, Wood M, Geffner L. Direct myocardial revascularization without extracorporeal circulation: experience in 700 patients. Chest 1991;100:312-6.

5. Borst C, Jansen EWL, Tulleken CA, et al. Coronary artery bypass grafting without cardiopulmonary bypass and without interruption of native coronary flow using a nove anastomosis site restraining device ("Octopus”). J Am Coll Cardiol 1996;27:1356-64.

6. Jansen EW, Borst C, Lahpor JR, et al. Coronary artery bypass grafting without cardiopulmonary bypass using the octopus meth- od: results in the first one hundred patients. J Thorac Cardiovasc Surg 1998;116:60-7. 7. Ascione R, Lloyd CT, Gomes WJ, Caputo $\mathrm{M}$, Bryan AJ, Angelini GD. Beating versus arrested heart revascularization: evaluation of myocardial function in a prospective randomized study. Eur J Cardiothorac Surg 1999;15: 685-90.

8. Ascione R, Lloyd CT, Underwood MJ, Gomes WJ, Angelini GD. On-pump versus off-pump coronary revascularization: evaluation of renal function. Ann Thorac Surg 1999;68:493-8.

9. Lloyd CT, Ascione R, Underwood MJ, Gardner F, Black A, Angelini GD. Serum S-100 protein release and neuropsychologic outcome during coronary revascularization on the beating heart: a prospective randomized study. J Thorac Cardiovasc Surg 2000; 119:148-54.

10. van Dijk D, Nierich AP, Jansen EW, et al. Early outcome after off-pump versus onpump coronary bypass surgery: results from a randomized study. Circulation 2002;104: 1761-6

11. Angelini GD, Taylor FC, Reeves BC, Ascione R. Early and midterm outcome after off-pump and on-pump surgery in Beating Heart Against Cardioplegic Arrest Studies (BHACAS 1 and 2): a pooled analysis of two randomised controlled trials. Lancet 2002; 359:1194-9.

12. Puskas JD, Williams WH, Duke PG, et al. Off-pump coronary artery bypass grafting provides complete revascularization with reduced myocardial injury, transfusion requirements, and length of stay: a prospective randomized comparison of two hundred unselected patients undergoing off-pump versus conventional coronary artery bypass grafting. J Thorac Cardiovasc Surg 2003;125: 797-808.

13. Subramanian VA, McCabe JC, Geller CM. Minimally invasive direct coronary artery bypass grafting: two-year clinical experience. Ann Thorac Surg 1997;64:1648-53.

14. SabikJF, Gillinov AM, Blackstone EH, et al. Does off-pump coronary surgery reduce morbidity and mortality? J Thorac Cardiovasc Surg 2002;124:698-707.

15. Nathoe HM, van Dijk D, Jansen EWL, et al. A comparison of on-pump and off-pump coronary artery bypass surgery in low-risk patients. N Engl J Med 2003;348:394-402. 
16. Diegeler A, Thiele H, Falk V, et al. Comparison of stenting with minimally invasive bypass surgery for stenosis of the left anterior descending coronary artery. $\mathrm{N}$ Engl J Med 2002;347:561-6.

17. Calafiore AM, Teodori G, Di Giammarco G, et al. Multiple arterial conduits withou cardiopulmonary bypass: early angiographic results. Ann Thorac Surg 1999;67:450-6. 18. Puskas JD, Thourani VH, Marshall JJ, et 41 .

al. Clinical outcomes, angiographic patency, and resource utilization in 200 consecu- tive off-pump coronary bypass patients. Ann Thorac Surg 2001;71:1477-84.

19. Hernandez F, Cohn WE, Baribeau YR. Inhospital outcomes of off-pump vs. on-pump coronary artery bypass procedures: a multicenter experience. Ann Thorac Surg 2001;72: 1528-34.

20. Bock JL. Cardiac troponin: how specific is specific? Am J Clin Pathol 1999;112:73941.

21. Magee MJ, Coombs LP, Mack MJ. Guidelines in selecting patients most likely to ben- efit from off-pump coronary artery bypass surgery. Circulation 2002;106:Suppl II:II-637. abstract.

22. Mack M, Bachand D, Acuff T, et al. Improved outcomes in coronary artery bypass grafting with beating-heart techniques. J Thorac Cardiovasc Surg 2002;124:598607.

23. Bonchek LI. Off-pump coronary bypass: is it for everyone? J Thorac Cardiovasc Surg 2002;124:431-4.

Copyright (c) 2004 Massachusetts Medical Society. 